\title{
A interincompreensão gera polêmica: alteridade e heterogeneidade nos discursos das cantoras Anitta e Pitty sobre comportamento sexual feminino
}

\section{Intercomprehension causes polemics: alterity and heterogeneity in the discourses of singers Anitta and Pitty regarding female sexual behavior}

Juliane de Araújo Gonzaga

UNESP

gonzagajuliane@gmail.com

Resumo: Este artigo se propõe a analisar a situação de polêmica entre as cantoras Anitta e Pitty, durante um programa televiso, em torno do comportamento das mulheres no domínio da sexualidade. Os objetivos específicos são: (i) verificar como a alteridade e a heterogeneidade delimitam posições discursivas; (ii) descrever a situação de polêmica e a mobilização de simulacros no processo de interincompreensão regrada e (iii) analisar a situação de polêmica e demonstrar que a alteridade e a heterogeneidade materializam embates legitimados historicamente no campo da sexualidade. Situado na Análise do Discurso francesa, este trabalho utiliza referencial teórico-metodológico baseado nos pressupostos de Authier-Revuz $(1990,1998)$, acerca da alteridade e da heterogeneidade enunciativa, e nas considerações de Maingueneau $(1993,2005)$ sobre o primado do interdiscurso e a polêmica como interincompreensão regrada. O método de análise baseia-se na descrição e interpretação de marcas linguísticas (glosas, pronomes, dêiticos, vocabulário) que materializam jogos de alteridade, movimentos de já-ditos e regras sobre o dizível e o indizível no discurso. Por fim, a análise conclui que os enunciados são 
heterogeneamente marcados e que as posições discursivas produzem situação de polêmica, pois são atravessadas por simulacros, estereótipos e embates históricos entre os gêneros no domínio da sexualidade.

Palavras-chave: discurso; alteridade; heterogeneidade; polêmica.

\begin{abstract}
This article investigates a polemic issue between the Brazilian singers Anitta and Pitty during a television show. The polemic was about the feminine behavior in relation to sexuality. The specific objectives are: (i) to verify how alterity and heterogeneity delimit discursive positions; (ii) to analyze a polemic issue and the use of simulacrums in the intercomprehension process; and (iii) to demonstrate that alterity and heterogeneity materialize some conflicts historically legitimated in the context of sexuality. Placed on the French Discourse Analysis, this research applies the theoretical and methodological arsenal based on the assumptions of Jacqueline Authier-Revuz (1990; 1998) about alterity and enunciative heterogeneity. This work also applies Dominique Maingueneau's reflections $(1993 ; 2005)$ concerning the primacy of interdiscourse and the polemic as an intercomprehension. The method of analysis is based on the description and interpretation of linguistics expressions (glosses, pronouns, deictics, lexis) that materialize alterity, interdiscourse movements and discourse regulation. In short, the analysis concludes that enunciation is heterogeneously marked and that discursive positions produce polemic situations for it expresses simulacrums, stereotypes and historic conflicts between genders in the context of sexuality.
\end{abstract}

Keywords: discourse; alterity; heterogeneity; polemic.

Recebido em 05 de setembro de 2015. Aprovado em 22 de janeiro de 2016. 


\section{Introdução}

Os discursos acerca dos papéis de gênero ${ }^{1}$ materializam-se em enunciados dispersos na história e atestam determinadas posições para homens e mulheres nas relações sociais. Historicamente, essas relações são marcadas não só por hierarquias, mas também por transformações quanto às formas de conceber os direitos civis, o comportamento sexual e os relacionamentos afetivos e familiares. Entretanto, é preciso considerar que essas mudanças não excluem regulações e interdições nesse domínio.

Atualmente no Brasil, há grande visibilidade da questão de gênero, em parte, devido ao retorno do feminismo pelas mídias digitais. A facilidade de manifestação de ideias e a popularidade do feminismo nesses espaços demonstram que, mesmo com mudanças no campo da intimidade, ainda existe polêmica quando o assunto é comportamento sexual, igualdade de gênero e machismo.

O estímulo para produção deste artigo veio do debate entre as cantoras Anitta e Pitty sobre a condição da mulher, no programa Altas Horas, veiculado pela Rede Globo em 6 de dezembro de 2014. Na ocasião, as cantoras estabeleceram situação de polêmica, uma vez que apresentaram leituras diferentes sobre o comportamento sexual feminino. A polêmica também repercutiu nas mídias digitais, em especial nas redes sociais, evidenciando que a "interincompreensão" entre sujeitos e determinados simulacros e estereótipos movimentam a discussão sobre machismo no Brasil.

Desse modo, propomos analisar a situação de polêmica entre as cantoras Anitta e Pitty com o intuito de compreender como, através de instância enunciativa, esses dizeres constituem posições para homens e mulheres no domínio da sexualidade. Na primeira parte do artigo, analisaremos o conjunto de enunciados produzidos pela cantora Anitta e, na segunda, o debate travado entre as duas cantoras.

Assim, nossos objetivos específicos são: (i) verificar como a alteridade e a heterogeneidade enunciativa delimitam posições discursivas para mulheres e homens nos dizeres da cantora Anitta; (ii)

\footnotetext{
${ }^{1}$ As relações de gênero são estabelecidas por meio de hierarquias e distinções entre homens e mulheres. Neste trabalho, assumimos a concepção de gênero como representação social do sexo, isto é, como constituição da identidade sexual na e pela relação entre membros da sociedade (LAURETIS, 1994).
} 
descrever a cena enunciativa instaurada por Pitty e Anitta atentando para os modos de enunciação e os efeitos de sentido; (iii) analisar a situação de polêmica e demonstrar que a mobilização de simulacros e a relação entre formações discursivas distintas contribuem para a tradução do Outro via processo de interincompreensão regrada.

Situados na Análise do Discurso francesa, assumimos neste trabalho a postura que visa a descrever o funcionamento discursivo, de modo a analisar a produção de sentidos pela língua como efeito de relação constitutiva com a ideologia e a história (PÊCHEUX, 1997). O referencial teórico-metodológico que mobilizaremos para a análise assenta-se nos pressupostos de Jacqueline Authier-Revuz (1990; 1998) e Dominique Maingueneau (1993) acerca da alteridade e da heterogeneidade enunciativa. Ademais, pautaremos as análises nas considerações de Maingueneau (2005) sobre o primado do interdiscurso e a polêmica como interincompreensão regrada.

Em consonância a essas propostas, analisaremos os enunciados produzidos pelas cantoras Anitta e Pitty no programa Altas Horas. A metodologia de análise se pautou inicialmente na seleção do corpus, composto de dados obtidos por meio de transcrição das falas. Para tanto, recorremos ao vídeo que registra a situação de polêmica disponível no site do programa, e realizamos o trabalho de transcrevê-lo. Tendo as falas transcritas na forma de enunciados, a análise se voltou para a descrição: (i) das marcas linguísticas que evidenciam o jogo de alteridade entre sujeitos (pronomes de referenciação); (ii) do movimento de já-ditos nos discursos; (iii) dos dêiticos e do vocabulário empregados pelos enunciadores; e (iv) das determinações históricas sobre o dizível e o indizível no discurso.

Desta feita, este trabalho pretende mostrar como os enunciados de Pitty e Anitta são heterogeneamente marcados - isto é, mostrar quais são os efeitos da inscrição do Outro no dizer do $\mathrm{Eu}$ - e como suas posições discursivas são atravessadas por embates legitimados historicamente no domínio da sexualidade e das relações de gênero.

\section{A alteridade e a heterogeneidade mostrada na construção de papéis de gêneros no dizer da cantora Anitta}

Neste trabalho, assumimos a concepção de discurso enquanto "dispersão de textos cujo modo de inscrição histórica permite definir como espaço de regularidades enunciativas" (MAINGUENEAU, 2005, 
p. 15). Os discursos não se constituem independentemente uns dos outros, e sim de forma regulada, no interior desse espaço de relações constantes com outros discursos. Logo, para compreender a formação de um discurso, é preciso voltar-se para o espaço de regularidade em que habitam os discursos e colocá-los em relação. É somente na relação entre discursos que podemos evidenciar a identidade deste ou daquele discurso: daí o conceito de interdiscurso.

Ao sustentar que o primado do interdiscurso possibilita a emergência de discursos e a produção de sentidos, Maingueneau (2005) compreende essa instância como a articulação de um universo discursivo, um campo discursivo e um espaço discursivo (p. 36). Assim, o interdiscurso compreende: (i) o conjunto de formações discursivas que interagem numa conjuntura histórica dada; (ii) o conjunto de formações discursivas que se encontram em concorrência e que se delimitam reciprocamente.

O conceito de "formação discursiva" tem sua importância no quadro da Análise do Discurso uma vez que compreende "um conjunto de regras anônimas, históricas, sempre determinadas no tempo e no espaço que definiram em uma época dada e para uma área social, econômica, geográfica ou linguística dada, as condições de exercício da função enunciativa" (FOUCAULT, 2012, p. 144). São essas regras que permitem compreender quais sentidos podem e devem ser enunciados por sujeitos situados historicamente.

No interior do interdiscurso admite-se que o discurso nasce das relações entre discursos que emergiram antes e em outros lugares. É na situação de interação e polêmica entre discursos, ou seja, no trabalho dos discursos sobre os outros, que se dá a constituição discursiva. Nesse sentido, pensar o discurso como resultado de interações entre discursos diferentes - produzidos por outros sujeitos e em épocas distintas - implica considerar o caráter heterogêneo de sua formação. Logo, todo discurso carrega em sua constituição outros discursos, tanto em movimentos de negação quanto de afirmação. Essa relação com o exterior se mostra, portanto, constitutiva e delimitadora da identidade do discurso (MAINGUENEAU, 1993).

Entretanto, a heterogeneidade não se limita à relação entre discursos outros. De fato, toda produção discursiva implica instância de enunciação com um sujeito do discurso que se posiciona como fonte enunciativa de um dizer. Ora, se todo discurso precisa de um sujeito que o enuncie e se todo discurso surge da relação entre outros discursos, o 
sujeito de um determinado discurso também entra em relação com sujeitos outros. Assim, no interdiscurso, sujeitos distintos podem estabelecer relações que delimitam aquilo que é interno e externo ao sujeito (Ibid.).

Segundo Maingueneau (1993, p. 93), a heterogeneidade promove ainda a "construção pelo locutor de níveis distintos [de enunciação] no interior de seu próprio discurso". A heterogeneidade possibilita então que no dizer de um sujeito haja enunciadores distintos, o que demonstra que a relação do sujeito com o Outro é marcada por vozes ${ }^{2}$ vindas de outros lugares. Trazer o Outro para o interior do enunciado promove a identidade daquele que enuncia, pois essa presença delimita as margens do Eu, representando aquilo que é aceito e/ou rejeitado pelo sujeito do discurso. Logo, o lugar ocupado pelo Eu sempre passa pelas fronteiras do Outro, pois o sujeito traz o exterior para o interior de seu discurso seja para afirmá-lo, seja para negá-lo33 (AUTHIER-REVUZ, 1990).

Nesse ponto, destacamos que a questão da heterogeneidade contribui também para problematizar a categoria de sujeito na Análise do Discurso. Por isso, apontamos aqui pressupostos de Authier-Revuz (1990) que, ao conceber o Outro em relação constitutiva com o Eu, questiona a concepção de sujeito como "fonte autônoma" do dizer e pontua que: "nesta afirmação de que, constitutivamente, no sujeito e no seu discurso está o Outro, reencontram-se as concepções do discurso, da Ideologia, e do inconsciente, que as teorias da enunciação não podem, sem riscos para a linguística, esquecer" (Id., 1990, p. 29, grifos no original).

Dessa forma, para pensar a presença do Outro no discurso, bem como sua relação constitutiva com o Eu, a autora articula pressupostos psicanalíticos, históricos, sociológicos e linguísticos. Essa articulação teórica contribui para os estudos da enunciação e do discurso na medida em que demonstra a necessidade de romper com o Eu da subjetividade

\footnotetext{
${ }^{2}$ Ao problematizar a heterogeneidade enunciativa, Maingueneau (1993) mobiliza pressupostos de Ducrot sobre a polifonia (conjunto heterogêneo de vozes do discurso). A polifonia é marcada no discurso pela presença de um locutor (aquele que é responsável pela enunciação, simbolizado por L) e de enunciadores (figuras do discurso cujos pontos de vista não coincidem com o do locutor; simbolizado por E). É nesse sentido que o autor afirma que o enunciador "pode pôr em cena, em seu próprio enunciado, posições diversas da sua" (MAINGUENEAU, 1993, p. 77).

${ }^{3} \mathrm{O}$ distanciamento e as marcas utilizadas para demarcar o que é do Eu e o que é do Outro consistem em movimentos de alteridade (AUTHIER-REVUZ, 1990).
} 
clássica - que o concebe como "senhor soberano", dono de seu dizer para, então, assumir uma concepção de sujeito descentrado.

A fim de descrever as heterogeneidades enunciativas, AuthierRevuz (1990, p. 25-26) assinala que elas podem ocorrer de forma mostrada ou constitutiva:

Heterogeneidade mostrada: aquela resultante da inscrição do Outro na sequência do discurso. Trata-se do discurso direto, das aspas, da glosa, do discurso indireto livre, da ironia. Tipo de heterogeneidade notadamente marcada no discurso pela referência explícita ao que é do Outro e ao que é do $\mathrm{Eu}$

$[\ldots]$

Heterogeneidade constitutiva: aquela que se refere à constituição do discurso, pois formado sempre de discursos outros e dispersos. Neste caso, não há na sequência do discurso marcas explícitas de sua relação com o exterior. A heterogeneidade aqui não é localizável nem representável.

A heterogeneidade do discurso mostra a opacidade da linguagem, uma vez que os sentidos não são facilmente apreendidos e delimitados. Além disso, as circunstâncias históricas e o tipo de relação que o sujeito estabelece com a linguagem são determinantes para a produção do sentido. Como esses fatores variam, é preciso ter em conta que a linguagem é plurissignificativa: os sujeitos não interpretam os sentidos da mesma maneira.

Soma-se a não-transparência da linguagem, a impossibilidade de o discurso ser original e neutro. Ao afirmar, junto com Bakhtin, que "as palavras são sempre as palavras dos outros", Authier-Revuz demonstra que a heterogeneidade está fundada no funcionamento dialógico da linguagem, pois sempre há um já-dito que reverbera nos discursos. Isto é, há uma profusão de "vozes sociais" que se emaranham no fio do discurso, num ir e vir constante e disperso. A heterogeneidade e a polifonia marcam todo dizer que se encontra sempre habitado, atravessado, carregado por discursos outros que circularam e ainda circulam na sociedade na forma de uma "dialogização interna do discurso" (Ibid., p. 26).

É importante destacar que a concepção de heterogeneidade constitutiva mantém ligações com a noção de interdiscurso. Logo, 
no que concerne à heterogeneidade, é possível identificar articulação entre as considerações de Authier-Revuz e Maingueneau. Isso porque a heterogeneidade do tipo constitutiva, tal como apontada por AuthierRevuz, é interpretada por Maingueneau como princípio característico da interdiscursividade.

Para Maingueneau (2005, p. 33), a heterogeneidade constitutiva

não deixa marcas visíveis: as palavras, os enunciados de outrem estão tão intimamente ligados ao texto que não podem ser apreendidos por uma abordagem linguística stricto sensu. Nossa própria hipótese do primado do interdiscurso inscreve-se nessa perspectiva de uma heterogeneidade constitutiva, que amarra, em uma relação inextricável, o Mesmo do discurso e seu Outro.

Logo, a heterogeneidade, além de representar a presença de discursos e sujeitos outros no fio do discurso, demonstra que o funcionamento discursivo se dá num movimento constante de já-ditos, numa profusão incessante de relações e, ainda, num permanente devir do sujeito.

Feitas essas considerações sobre heterogeneidade e alteridade como constitutivas do Eu, analisaremos, neste primeiro momento, os enunciados produzidos pela cantora Anitta sobre o comportamento sexual feminino. Visto que a fala da cantora é marcada por jogos de alteridade - há marcas evidentes de distanciamento entre o Eu e o Outro -, justificamos que o aporte teórico mobilizado nesta primeira parte da análise se pauta, sobretudo, nas considerações de Authier-Revuz sobre a heterogeneidade mostrada, porque contribuem para a descrição de materialidades linguísticas, que funcionam como negociação dos sentidos daquilo que é interior e exterior ao sujeito da enunciação. As categorias específicas que analisaremos são: formas de referenciação aos sujeitos; dêiticos temporais e espaciais e verbos modalizadores, que nos auxiliarão a identificar movimentos de distanciamento e alteridade nos enunciados.

Antes de iniciarmos a análise, algumas elucidações sobre a situação de enunciação são necessárias. Os enunciados da cantora Anitta foram produzidos com a finalidade de responder às questões: qual é a sua opinião sobre o comportamento sexual na atualidade? Os homens costumam assediá-la muito? As perguntas foram feitas pelo 
apresentador do programa Altas Horas, Serginho Groisman, e emergiu durante a gravação do programa, cujo tema abordado foi "a condição da mulher brasileira na contemporaneidade". Para a gravação do programa, a plateia foi composta somente de homens, e as entrevistadas convidadas foram apenas mulheres. Nesse sentido, podemos pressupor que os conhecimentos compartilhados entre os interlocutores sobre a questão da mulher são distintos e heterogêneos.

A seguir, os enunciados produzidos pela cantora Anitta (PROGRAMA ALTAS HORAS, 2014):

(1)

Eu tenho essa parte do show que eu canto a música dela [Flora Mattos] e eu chamo os caras no palco para dançar comigo e as reações são as mais inusitadas possíveis e nada previsíveis. Mas eu acho que a grande questão aqui hoje é que as mulheres lutaram tanto para ter os mesmos direitos que os homens que quando chegou no momento que elas tiveram, "Ah, o salário igual, a mulher também vota, a mulher também tem emprego”, chegou uma hora que ela quis tomar conta da situação. (informação verbal).

Atentemos inicialmente para a cena enunciativa. $\mathrm{O}$ enunciador instaura a enunciação por meio de dêiticos, que fazem referência ao comportamento da mulher na atualidade: "a grande questão aqui hoje". A dêixis também é marcada pela inscrição do Outro no enunciado, assinalado como "as mulheres" e situado em distância ao Eu: "eu acho que [...] as mulheres". O modo de demarcar sua posição demonstra que o sujeito não se situa no mesmo lugar que o Outro. Isto é, ainda que enquanto sujeito empírico o enunciador seja mulher, discursivamente ele se distancia e não se identifica com a posição assumida pela mulher.

Quanto à interdiscursividade, o enunciador materializa o retorno de já-ditos sobre a condição política da mulher, mais especificamente, aqueles do movimento feminista que historicamente se constituem como luta das mulheres por direitos iguais aos dos homens: "as mulheres lutaram tanto para ter os mesmos direitos". Nessas sequências, ainda, há marcas de heterogeneidade, pois o Eu introduz um discurso relatado em seu dizer - presumido como relatado pela mudança no tom da fala do sujeito enunciador, que o introduz como se fosse comentário feito 
por uma terceira pessoa: "Ah, o salário igual, a mulher também vota, a mulher também tem emprego...".

Ao inscrever o Outro no seu dizer, o sujeito retoma discursos produzidos antes e em outros lugares, uma vez que faz reverberar nas materialidades linguísticas acontecimentos históricos como o movimento sufragista e feminista, cujos pressupostos são a igualdade de direitos (voto, trabalho etc.). Ademais, no que concerne à igualdade, o sujeito enunciador a constitui como algo certo, dado e concluído através de um dêitico temporal "quando chegou no momento que elas tiveram [os mesmos direitos]".

Nesses enunciados, o dizer do Outro é inscrito no dizer do Eu como uma tentativa de marcar uma exterioridade - aquilo que não pertence ao $\mathrm{Eu}$ - para determinar o ponto de vista do sujeito enunciador. A exterioridade constitui então a interioridade, pois, ao refutar uma posição enunciativa, o enunciador delimita sua própria posição na tentativa de restringir os sentidos e na pretensão "ilusória" do sujeito de homogeneizar o discurso. Assim, o Outro contribui para o acabamento do Eu como forma de estabelecer o UM da enunciação (AUTHIER-REVUZ, 1998).

É o caso, por exemplo, do comentário "as mulheres lutaram tanto para ter os mesmos direitos que os homens que quando chegou no momento que elas tiveram, chegou uma hora que ela quis tomar conta da situação", que pode ser considerado procedimento de conotação autonímica. Isto é, o dizer de Anitta faz referência a um discurso exterior - o discurso do Outro - a fim de demarcá-lo como "corpo estranho" a seu discurso, como avesso a seu ponto de vista (AUTHIER-REVUZ, 1998).

Além disso, ao inscrever o Outro (homens e mulheres) em seu comentário, o sujeito enunciador estabelece uma comparação, evidenciando a existência de posições diferentes para cada um deles. É o que podemos verificar nas materialidades: "as mulheres lutaram tanto para ter os mesmos direitos que os homens que quando chegou no momento que elas tiveram chegou uma hora que ela quis tomar conta da situação". Nesse caso, ao modalizar volitivamente a posição da mulher em relação ao homem, o sujeito enunciador demonstra que o Outro (mulher) pretende ocupar o lugar que não corresponde à igualdade entre os gêneros, e sim à superioridade, pois "quis tomar conta da situação".

Desse modo, o enunciador faz ecoar um pré-construído, ou seja, um "já-lá que impõe uma realidade e um sentido sob a forma de universalidade" (PÊCHEUX, 1997, p. 164). O pré-construído mobilizado 
pelo enunciador demonstra que nas relações de gênero sempre algum deles ocupa posição privilegiada: trata-se de um pré-construído ligado à hierarquia dos gêneros. Esse já-lá marca, por exemplo, o discurso patriarcal $^{4}$ que situa o homem em posição superior à mulher, atribuindolhe controle nas relações familiares, jurídicas, políticas etc.

Nos discursos patriarcais e feministas, por exemplo, o "querer superioridade" marca a posição enunciativa do homem e não da mulher. Entretanto, ao mobilizar o pré-construído da "hierarquia de gêneros", o Eu não se posiciona em concordância ao discurso patriarcal, tampouco em aliança ao discurso feminista. Os sentidos históricos ligados à "hierarquia de gêneros" são atualizados aqui para deslocar o desejo de superioridade atribuído aos homens pelo discurso feminista, por exemplo - para situá-lo como pretensão das mulheres. A singularidade do enunciado está, então, na demarcação das posições do Outro [homens e mulheres] no discurso: aqui é a mulher que quer tomar conta da situação e não o homem.

Por outro lado, os enunciados de Anitta fazem ecoar sentidos dispersos ligados à conjuntura histórica atual, em que a estrutura familiar brasileira passa por transformações que situam a mulher também como possível líder do núcleo familiar. As mudanças nas relações de gênero não ocorreram somente no campo da sexualidade e da intimidade, mas também na estrutura da família de classe média que, em casos de divórcio ou não, determina a mulher como chefe (RIBEIRO, 2005).

Desse modo, a interdiscursividade e os modos de enunciação produzem o seguinte efeito de sentido no posicionamento do sujeito enunciador: se depois de terem conquistado os mesmos direitos, elas quiseram tomar conta da situação, o responsável pela desigualdade dos gêneros não são os homens, e sim as mulheres.

As materialidades apresentam marcas de heterogeneidade mostrada - o Eu traz o Outro de forma explícita -, movimento do sujeito que representa operação de diferenciação e especificação do sentido. Segundo Authier-Revuz (1998), as formas de representação da heterogeneidade também podem ser denominadas "não-coincidências" do dizer, termo que engloba tanto a heterogeneidade mostrada quanto a constitutiva.

\footnotetext{
${ }^{4}$ Trata-se, por exemplo, do modelo que constitui a figura masculina como chefe do clã e que permeia os modos de organização tribal e as estruturas elementares de parentesco. Para mais esclarecimentos ver Bourdieu (2002) e Lévi-Strauss (1982).
} 
Essa gestão de dizeres representativos do "não-um" (da heterogeneidade do discurso) aparece não como decorrência de uma intencionalidade do sujeito, e sim como forma de "negociação obrigatória de todo enunciador com o fato das não-coincidências fundamentais que atravessam seu dizer" (Ibid., p. 21). É essa negociação, ou seja, essa operação do Eu sobre o dizer do Outro na tentativa de formar o UM do discurso que dá ao sujeito a ilusão de controlar seu dizer e circunscrever os sentidos.

Os discursos apresentam realizações diversas de negociação que manifestam imagens que os sujeitos produzem de si mesmos e do Outro, bem como as posições enunciativas próprias a sujeitos particulares e a gêneros discursivos. Considerando a negociação de sentidos estabelecida entre o Eu e o Outro, analisemos os enunciados a seguir:

(2)

Ah não! Eu [mulher] que vou e pego cinquenta e eu que...". Eu não acho bonito pegar cinquenta nem o homem nem a mulher, não acho bonito ninguém sair e pegar cinquenta. Mas a mulher acabou querendo tomar o lugar do homem em todas as situações. Só que eu acho que é o instinto masculino ele também querer proteger, querer cuidar, querer fazer o cavalheiro, a parte do cavalheiro, que é um instinto masculino e que agora o homem fica desestimulado. (grifos nossos).

$\mathrm{O}$ enunciador inscreve o discurso do Outro (mulher) no seu discurso, fazendo um uso distinto desse dizer. Isso porque o discurso relatado "Ah não! eu [mulher] que vou e pego cinquenta e eu que..." emerge no enunciado de modo a produzir o ponto de vista do enunciador sobre esse comportamento sexual na forma de comentário avaliativo: "Eu não acho bonito". Assim, o enunciador mobiliza o discurso relatado para delimitar seu posicionamento em relação ao Outro (mulher) e para moldar sua presença no discurso em termos do indizível e do interdito, ou seja, para determinar essa conduta como algo que não se pode e não se deve fazer.

Ainda sobre a inscrição do discurso do Outro no discurso do Eu, verificamos uma sequência gramatical do tipo exclusiva:

[Eu (mulher) que faço X e não ele (homem) que faz X] 
Nessa sequência, o Eu retoma já-ditos e transformações do domínio da intimidade, tais como a flexibilização de regras e a possibilidade de a mulher exercer a sexualidade fora do casamento por exemplo. Além disso, o discurso relatado - $[\mathrm{Eu}$ (mulher) que pego cinquenta, e não eles (homens)] - refuta uma regularidade discursiva que constitui o homem como sujeito autorizado a ter grande número de parceiras sexuais. O discurso relatado demonstra, portanto, a coexistência de regras mais flexíveis ao homem e as transformações nas regras daquilo que é permitido ou não no comportamento das mulheres. As transformações do dizível no comportamento sexual feminino são manifestas pelo enunciado que corrobora que elas também passaram a "poder pegar cinquenta", ação antes exclusiva dos homens: "Ah não! Eu [mulher] que vou e pego cinquenta".

Entretanto, o efeito de refutação a esse "poder fazer" do homem não emerge aqui como dizer do $\mathrm{Eu}$ (Anitta), e sim como o dizer do Outro (mulheres). Isto é, não é o Eu que refuta essa postura masculina, e sim o Outro (mulher) através do dizer do $\mathrm{Eu}$ (Anitta). Com isso, o Eu constitui seu ponto de vista em relação ao Outro: se a mulher refuta a exclusividade do homem de "pegar cinquenta", o Eu cita a posição do Outro, distanciando-se dessa refutação e delimitando seu lugar fora dessa oposição ao comportamento sexual masculino.

Além disso, a negociação do enunciador é evidente nas materialidades "Eu não acho bonito pegar cinquenta nem o homem nem a mulher, não acho bonito ninguém sair e pegar cinquenta", em que o sujeito procura explicar os sentidos de sua avaliação, de modo a não aplicar seu ponto de vista somente ao gênero feminino. A tentativa de estender sua avaliação a todos os gêneros "não acho bonito ninguém sair e pegar cinquenta" corresponde à tentativa de atribuir regras de forma "igual" aos sujeitos e, por conseguinte, de evitar sentidos de "desigualdade" em seu dizer.

Contudo, o enunciado seguinte traz a conjunção adversativa "mas" que introduz ponto de vista oposto ao dizer anterior, funcionamento gramatical que produz sentidos contraditórios: "Eu não acho bonito ninguém sair e pegar cinquenta. Mas a mulher acabou querendo tomar o lugar do homem em todas as situações". O efeito de contradição está no modo de enunciar os posicionamentos de homens e mulheres: no primeiro momento, o Eu constitui o indizível e o interdito para ambos os gêneros 
"eu não acho bonito ninguém sair e pegar cinquenta", situando-os no mesmo patamar de regras de comportamento. Depois, porém, separa os gêneros fazendo emergir regulações históricas que determinam aquilo que é próprio ao homem e não à mulher: "Mas a mulher acabou querendo tomar o lugar do homem em todas as situações".

Assim, o uso da conjunção adversativa produz sentido de contradição com o enunciado anterior, pois o enunciador atesta que nem homens nem mulheres podem pegar cinquenta, mas é a mulher que faz algo que não é do seu lugar, da sua posição. A interdição sobre o comportamento sexual de homens e mulheres é, portanto, contraditória porque o enunciador inicialmente interdita ambos os gêneros para, em seguida, manter a regulação somente à mulher.

Além disso, nas sequências discursivas em (2), verificamos uma repetição na forma de modalizar a postura da mulher em relação ao homem:

- "[...] chegou uma hora que ela quis tomar conta da situação".

- "Mas a mulher acabou querendo tomar o lugar do homem em todas as situações".

O modo como o Eu inscreve o Outro em seu enunciado demonstra que o "querer" modaliza a posição da mulher em relação ao lugar do homem. Dentre as possibilidades de modalização do Outro (mulher), o sujeito enunciador o constitui volitivamente, e não de forma epistêmica (capacidade, permissão), tampouco de forma deôntica (obrigação, dever) (NEVES, 2006). A escolha do léxico aqui é significativa, pois é atravessada por embates sociais entre os gêneros, que remontam à questão do machismo. Ao dotar o Outro (mulher) de um "querer tomar o lugar do homem" o enunciador o situa fora de um poder, ou seja, exime-o da possibilidade e/ou da permissão de agir de forma semelhante ao Outro (homem).

Essa forma de constituir a posição do Outro (mulher), de acordo com o contexto histórico atual, pode ser interpretada da seguinte maneira: apesar das transformações no campo da intimidade e da flexibilização das normas de conduta para as mulheres (GIDDENS, 1992), no âmbito daquilo que é dizível no comportamento sexual feminino ainda circulam discursos tradicionais de uma moral religiosa e familiar. Com efeito, discursos flexíveis convivem com discursos conservadores sem que um 
exclua o outro, e sim de forma relacional, pois todo dizer se relaciona a outro seja para refutá-lo, admiti-lo, repeti-lo, transformá-lo.

Situar o Outro dessa forma (enquanto sujeito que "quer tomar o lugar do homem"), numa cena enunciativa em que a igualdade de gêneros é dada como certa, demonstra o papel de já-ditos na construção da posição da mulher nesses enunciados e a condição descentrada do sujeito. Justificamos essas considerações pelo fato de o sujeito enunciador não conseguir se esquivar de determinações sócio-históricas ao produzir seus enunciados. O dizer do Eu é constituído de dizeres outros (produzidos antes e em outros lugares da história) e atravessado por embates sociais diferentes, tais como o conflito entre as feministas, a Igreja e o modelo patriarcal, que colocam em cena a existência de regulações mais rígidas às mulheres do que aos homens.

A heterogeneidade também marca os enunciados "Só que eu acho que é o instinto masculino ele também querer proteger, querer cuidar, querer fazer o cavalheiro, a parte do cavalheiro, que é um instinto masculino e que agora o homem fica desestimulado". O sujeito enunciador inscreve o Outro (homem) em seu dizer nos termos do "amor romântico", modelo em que a sexualidade fica em segundo plano, e a questão afetiva e matrimonial impõem-se como principais. O modelo de comportamento invocado pelo enunciador é resultante de um simulacro, ou seja, de uma tradução que o Eu faz do Outro a partir das regras que habitam seu dizer (MAINGUENEAU, 2005).

Nessas sequências, o Outro (homem) é lido e construído por meio de ações consideradas como próprias do instinto masculino: proteger e cuidar. É relevante salientar que o instinto masculino aqui é traduzido dessa forma, pois a grade semântica (conjunto de competências e regras do dizível) que determina essa leitura inscreve-se numa formação discursiva atravessada por uma moral familiar e "romântica".

As materialidades linguísticas evidenciam, inclusive, a legitimação de estereótipos e o deslocamento de posições atribuídas historicamente às mulheres. O enunciado "só que é o instinto masculino ele também querer proteger, querer cuidar [...] e que agora o homem fica desestimulado" constitui o homem mobilizando estereótipos que são socialmente atribuídos à mulher (maternal, sensível, afetuosa etc.), uma vez que produz que o inclui nesse "instinto" "ele também querer proteger, cuidar". Assim, não é só a mulher que tem instinto de proteger e cuidar do parceiro, o homem também é dotado dessas inclinações. 
Identificamos ainda a mobilização de estereótipos quando o sujeito diz que "agora o homem fica desestimulado" a proteger a mulher. Há estereótipos produzidos socialmente que constroem a mulher como ser frágil e sensível que necessita de proteção, em oposição ao homem, ser forte e protetor do clã. Ao dizer que o homem fica desestimulado, o enunciador refere-se ao contexto histórico atual, em que parte das mulheres não se constitui mais de acordo com esse estereótipo "frágil" nas relações sexuais e afetivas. As materialidades evidenciam, novamente, um deslizamento de sentidos: de um lugar passivo a mulher passou a ocupar posição ativa nos relacionamentos. Em suma, o homem não tem mais vontade de desempenhar proteção e cuidado, porque a mulher modificou sua postura de protegida/cuidada para a posição de iniciativa/conquista.

Neste primeiro momento da análise, constatamos que os enunciados analisados são marcados por práticas que demarcam posições específicas para os gêneros. Nesses termos, os enunciados evidenciam sentidos históricos sobre aquilo que é permitido ao masculino e ao feminino, de modo que o enunciador, em relação de alteridade com o Outro, mobiliza já-ditos e desloca determinados sentidos para demarcar diferenças nos papéis exercidos pelo homem e pela mulher no campo da sexualidade na contemporaneidade.

$\mathrm{Na}$ seção a seguir, pretendemos problematizar como o sujeito desta formação discursiva se relaciona com o sujeito de formação discursiva distinta. Ou seja, a análise atentará para a relação entre os enunciados da cantora Anitta e os da cantora Pitty.

\section{Polêmica entre sujeitos: a interincompreensão regrada e a tradução do Outro na forma de simulacros}

Nesta segunda parte da análise, analisaremos como os enunciados de Anitta foram interpretados por interlocutor participante da situação de enunciação: a cantora Pitty, uma das mulheres entrevistadas no programa. É preciso levar em conta que, para as proposições de Anitta, o posicionamento de Pitty se deu na forma de contestações. A situação de enunciação caracteriza-se, portanto, como debate, uma vez que Anitta e Pitty defendem seus pontos de vista de forma intercalada em turnos de proposição-réplica. Isso nos leva a constatar que, ainda que os sujeitos da enunciação sejam do gênero feminino, os conhecimentos de mundo compartilhados entre eles são diferentes e heterogêneos. 
Considerando que, neste momento analítico, os enunciados a serem analisados materializam interpretação do posicionamento do Outro a partir de restrições sobre o que se pode e se deve dizer a partir de lugares específicos, mobilizaremos fundamentação teórica de Maingueneau (2005) sobre a polêmica como processo de interincompreensão regrada. Esses pressupostos podem contribuir para identificar as diferentes formas de tradução do Outro - seja por simulacros, seja por restrições semânticas - e, ainda, para evidenciar que toda situação de polêmica é efeito da relação entre formações discursivas antagônicas.

Conforme assinala o autor, o jogo de alteridade contribui para o processo de acabamento do sujeito e de "tradução" do Outro. Ao relacionarem-se os sujeitos na enunciação, também entram em relação suas respectivas formações discursivas, o que pode resultar em situações de confronto, antagonismo, aliança, adesão etc. Assim, quando se fala de tradução do Outro pelas categorias do Mesmo entra em cena a dissimetria entre as formações discursivas, uma vez que "cada formação discursiva tem uma maneira de interpretar seu Outro" (MAINGUENEAU, 2005, p. 108). O antagonismo entre dois posicionamentos discursivos surge, então, como situação não estável pois dependente da relação que o Mesmo estabelece consigo mesmo e com o Outro.

O Mesmo se relaciona com o Outro pela linguagem através de comentários, citações, discursos relatados (heterogeneidade mostrada), bem como de movimentos do interdiscurso no fio do discurso (heterogeneidade constitutiva). A análise da relação Mesmo-Outro deve se voltar, então, para os planos do discurso: o léxico, o modo de enunciação, o interdiscurso, em suma, os níveis que se integram numa semântica global (Ibid.). É através desses planos do discurso que a alteridade se dá, uma vez que eles evidenciam: a forma como se rompe a continuidade do Mesmo; qual é o corpo verbal do Outro; e o modo como o Mesmo incorpora e/ou rejeita o Outro.

Dessa forma, quando dois discursos se delimitam reciprocamente podemos dizer que há um processo de "tradução" particular. Não se trata de uma tradução de uma língua natural para outra, e sim de uma formação discursiva a outra. A leitura que se faz do Outro ocorre na mesma língua, porém recobre restrições semânticas distintas, o que contribui para uma "incompreensão" entre os sujeitos. Nesse ponto, é interessante retomar a expressão "diálogo de surdos", para mostrar como protagonistas situados no mesmo idioma podem "não falar a mesma língua". 
Assim, o efeito de incompreensão se dá "quando uma formação discursiva faz penetrar seu Outro em seu próprio interior", ou seja, quando “ela está apenas ‘traduzindo' o enunciado deste Outro, interpretando-o através de suas próprias categorias" (MAINGUENEAU, 1993, p. 120). Além disso, ao citar o Outro, o Mesmo pode entrar em conflito com esse corpo citado, que "se expulsa por si próprio, pelo simples fato de que ele se alimenta de um universo semântico incompatível com aquele da enunciação que o envolve" (Id., 2005, p. 112).

A polêmica surge então como efeito do processo de "interincompreensão regrada", chamada regrada justamente por obedecer a regras que definem a identidade das formações discursivas em relação. Com isso, o efeito de "mal-entendido" se dá sistematicamente, pois é constituído em espaço discursivo de restrições semânticas antagônicas. A relação entre formações discursivas antagonistas produz, assim, incompreensão entre sujeitos, pois determina aquilo que "se deve falar e não se deve compreender" (Id., 1993, p. 121).

Nesse sentido, o funcionamento polêmico do discurso se dá através da tradução que o Mesmo faz de si e do Outro. Essa dupla tradução implica a oposição de dois conjuntos de categorias semânticas no interior de uma formação discursiva: as reivindicadas (positivas) e as recusadas (negativas). As unidades de sentido do Outro sempre se relacionam com as do Mesmo na forma de rejeição. Logo, para produzir sua identidade, o discurso do Mesmo "só pode relacionar-se com o Outro através do simulacro que dele constrói" (Ibid., p. 122).

Ainda sobre o funcionamento discursivo da polêmica, podemos dizer que, embora produzido pela divergência de pontos de vista, supõe uma convergência quando se trata de pensar na existência de "um conjunto ideológico comum" (Id., 2005, p. 115). Isto é, existe um contrato entre os "adversários" uma vez que se presume um código transcendente, que é reconhecido por eles como responsável por decidir o que é justo e injusto. Os sujeitos postulam a figura de um "árbitro", de uma instância "neutra" exterior a eles, ficção que sustenta a polêmica e que é necessária para a crença de cada adversário nas leis de seu campo discursivo (Ibid.).

Tendo em vista essas considerações, observemos o debate estabelecido entre Pitty e Anitta, e como a relação entre suas formações discursivas contribuem para processo de interincompreensão e polêmica. As materialidades linguísticas que serão investigadas consistem em pronomes 
de referenciação, dêiticos temporais e espaciais, vocabulário e glosas, que foram utilizados pelos sujeitos da enunciação para apontar a situação de igualdade entre os gêneros segundo seus respectivos pontos de vista.

(3)

Pitty: Anitta, só uma ressalva, nós ainda não temos os mesmos direitos. Nós não ganhamos o mesmo salário.

Anitta: Mas nós já chegamos quase...

Pitty: Não. Quase não élá. Vamo começar por aí. Eu acho, eu acho que a gente ainda tem muito pra conquistar. $A$ partir do momento em que a gente questiona uma plateia masculina "Se uma mulher sair com os amigos é ruim", por exemplo, não tem nada a ver, não é especifico. Mas que isso causa tanta comoção, eu acho que a gente está longe.

Anitta: Não, não, longe no sentido do machismo, né?

Pitty: Mas é disso que a gente tá falando.

Anitta: Não do machismo, né? Do machismo do homem achar que, no sentido não dos direitos civis, sabe, dos direitos "cíveis".

Pitty: Mas mesmo nos direitos cíveis.

Anitta: Dos direitos cíveis. Mas assim do machismo do comportamental. O homem achar que a mulher "Ah, não pode ir pra lá, não pode usar roupa curta, não pode não sei o quê". (informação verbal).

Inicialmente, observamos que o modo de enunciação se modifica quando outro enunciador entra em cena, uma vez que esse segundo enunciador (Pitty) constitui-se como pessoa do discurso na forma de "nós": "Anitta, só uma ressalva, nós ainda não temos os mesmos direitos. Nós não ganhamos o mesmo salário". Também há momentos em que Pitty mobiliza as formas de primeira pessoa "eu" e "a gente" (mulheres) no mesmo enunciado, como, por exemplo, em: "Eu acho que a gente está longe". Esse modo de enunciação produz sentidos singulares se o compararmos àquele do primeiro enunciador (Anitta), que se referia a si mesmo em primeira pessoa ("eu"), e à mulher em terceira pessoa ("a mulher/as mulheres" e "ela/elas").

A diferença no modo de assumir-se enquanto sujeito de discurso, nesta cena de enunciação, é significativa, pois materialização linguística 
da imagem de si que faz o enunciador. Enquanto Anitta nos enunciados anteriores não se inclui em "elas/as mulheres", Pitty se inclui na primeira pessoa do discurso (a gente/nós mulheres) e produz efeitos de adesão e identificação. Entretanto, nesse segundo momento, em que surge um coenunciador na cena, Anitta modifica o modo de marcar sua pessoa no discurso. Assim como Pitty, Anitta passa a constituir a imagem de si por meio de "nós", porém o faz construindo uma posição diferente daquela construída pelo coenunciador: "Mas nós já chegamos quase" em oposição ao dizer de Pitty, "Eu acho que a gente ainda está longe".

Neste ponto, destacamos a instauração da dêixis em que os enunciadores constroem seu discurso considerando aspectos como a distância e a proximidade da situação de igualdade entre os gêneros, o que é marcado na enunciação pelos dêiticos de tempo e espaço. O modo como constroem as posições da mulher no contexto de igualdade de gêneros demonstra que para Anitta essa situação está próxima, em oposição a Pitty, que a constitui como algo distante. Tendo em vista a situação de "igualdade/desigualdade de gêneros", Anitta busca delimitar os sentidos de seu dizer, explicando-os através de metaenunciações: (i) "Não, não, longe no sentido do machismo, né?" e (ii) "Não, do machismo, né? Do machismo do homem achar que, no sentido não dos direitos civis, sabe, dos direitos cíveis".

Nessas sequências, identificamos aquilo que Authier-Revuz (1998, p. 25) classifica como uma "não-coincidência das palavras consigo mesmas". Esse tipo de não-coincidência decorre do equívoco entre enunciadores sobre o sentido de uma palavra, de modo a ser marcada no fio do discurso através de tentativa de delimitação de um sentido. É o caso da não-coincidência que visa a dar "respostas de fixação de um sentido: $X$, no sentido de $p$; $X$, não no sentido de q" (AUTHIER-REVUZ, 1998 , p. 25, grifo no original). No dizer de Anitta, então, a necessidade de demarcar sentidos recai sobre o dêitico "longe", que é mobilizado com o sentido de distância que as mulheres estão da igualdade.

Visto que Pitty considera que "as mulheres estão longe da igualdade", Anitta tenta fixar sentidos produzindo comentários sobre o dizer do coenunciador, a partir das restrições semânticas da formação discursiva que habita o seu dizer. Logo, para explicar o sentido de "estamos longe", Anitta explica: (i) "Não, não, longe no sentido do machismo"; (ii) "Longe no sentido não dos direitos civis, dos diretos cíveis". As materialidades evidenciam a existência de sentidos outros 
que habitam os dizeres, mais especificamente, a polissemia em torno do dêitico "longe". Com isso, verificamos que há apreensões diferentes dos sentidos por parte dos enunciadores (evidência do não-um do discurso) que é restringida pelo comentário de Anitta, que, por sua vez, interpreta e fixa o dêitico "longe" somente na condição do machismo (tentativa de instaurar o UM do discurso).

Além disso, os enunciadores compreendem diferentemente a situação da igualdade entre os gêneros, o que decorre de um processo de interincompreensão regrada. Essa situação evidencia a repartição de sentidos sobre a qual repousa todo discurso: "de um lado, os semas 'positivos', reivindicados; de outro, os semas 'negativos', rejeitados" (MAINGUENEAU, 2005, p. 103). Nesse sentido, os enunciadores mobilizam semas, positivos e negativos, que se opõem e configuram as possibilidades de leitura que cada um deles pode fazer de um tema. Os semas são mobilizados, ainda, em função das regras de suas formações discursivas quanto ao que se pode e se deve dizer no contexto das relações de gênero.

Para Anitta, a distância da igualdade está somente no machismo comportamental e não nos direitos cíveis, ao passo que, para Pitty, toda a discussão da desigualdade está compreendida nos termos do machismo. As leituras produzem então efeitos de "incompreensão" e "mal-entendido" quanto ao tema da discussão empreendida: "Mas é disso [machismo] que a gente tá falando". Ademais, destacamos que lá onde Anitta vê igualdade [nos direitos cíveis], Pitty vê desigualdade, o que pode ser justificado pelas materialidades: "Anitta: [Estamos longe] no sentido não dos direitos civis, sabe, dos direitos cíveis" em oposição a "Pitty: Mas mesmo nos direitos cíveis". Nessas condições, Anitta vê "igualdade" (sema positivo) nos direitos cíveis e "desigualdade" (sema negativo) no machismo comportamental; ao passo que Pitty vê "desigualdade" (sema negativo) tanto nos direitos cíveis quanto no machismo comportamental.

Tendo em vista a interdiscursividade, verificamos que os enunciados estabelecem relações com discursos anteriores e atualizam uma oposição histórica: os discursos machistas em oposição aos discursos feministas. As sequências demonstram, ainda, que o sujeito mobiliza a presença do Outro no seu dizer num movimento de negação, em que há rejeição de determinados sentidos e afirmação de outros para a delimitação do Mesmo. É o que ocorre no dizer de Anitta, por exemplo, em que o machismo é rejeitado e a igualdade é afirmada no plano dos direitos civis. 
Visto que a presença do Outro no discurso se dá somente a partir de uma leitura antagônica, verificamos que os sujeitos desta cena enunciativa mobilizam simulacros na tentativa de demarcar sua posição e seu ponto de vista sobre o tema. É o que ocorre nos enunciados a seguir, que materializam situação de polêmica em função de posições discursivas opostas quanto ao comportamento sexual da mulher:

(4)

Anitta: Mas eu acho que uma coisa é o comportamento, o machismo do homem que não sei o quê. E outra coisa que eu acho é o respeito que a mulher tem que dar pra ela mesma, porque se a mulher não se respeitar, ninguém vai respeitar a mulher. É...

Pitty: Mas isso homem e mulher, né, qualquer ser humano, dissociado de gênero. Porque o que se diz de uma mulher de respeito é diferente do que se diz de um cara de respeito. Então, isso me incomoda. Isso é uma coisa que me incomoda, por exemplo, sei lá, tipo aquela história do texto, tipo isso. As pessoas te veem no palco rebolando de roupa curta e acham que você está disponível.

Anitta: Exatamente.

Pitty: Independente do trabalho, independente de qualquer coisa. Pra mim isso é sair na defesa de um comportamento que se fosse masculino, ninguém questionaria. Então pra mim já começa por aí.

Anitta: Eu continuo acreditando que a mulher precisa se dar o respeito. Eu falo isso porque eu tô, eu vivo a noite, a boate, e eu vejo um comportamento feminino que dá margem realmente pra o homem achar coisa $x$ ou y da mulher etc. Então, assim, o que eu costumo ver quando eu tô na noite, quando eu tô na boate, ai eu penso, "mas gente, como é que o homem não vai tratar uma mulher assim se várias delas estão se comportando dessa maneira”.

Pitty: Anitta, tá errado!

Anitta: Eu não concordo...

Pitty: Ele está errado!

Anitta: Eu não concordo... 
Pitty: Ele não tem que achar ou achar nada! Quem tem que fazer o que você quer é você, cara! (informação verbal).

Nos enunciados anteriores, verificamos as diferentes leituras que os enunciadores fazem do comportamento sexual da mulher. A leitura de Anitta situa o homem na condição de dizer o que "é próprio ou impróprio" nas atitudes da mulher, uma vez que seu dizer autoriza o homem a desempenhar determinadas ações como consequência do comportamento feminino: (i) "E eu vejo um comportamento feminino que dá margem realmente pra o homem achar coisa $\mathrm{x}$ ou $\mathrm{y}$ da mulher etc."; (ii) "aí eu penso, 'mas gente, como é que o homem não vai tratar uma mulher assim se várias delas estão se comportando dessa maneira?""

Os enunciados mobilizam pré-construídos sobre o comportamento feminino, pois Anitta interpreta a posição da mulher segundo sentidos históricos que a situam nos termos de "dever" seguir um dado modelo de conduta. Ainda nesse sentido, a regulação do comportamento sexual ("ter que se dar o respeito") é atribuída, no dizer de Anitta, somente à mulher e não ao homem. Isso porque o enunciador não o inclui nesse modelo de conduta, tampouco se posiciona contrariamente a regras que recriminam a mulher em função de seu comportamento.

Em outro momento, o dizer de Anitta produz efeito de comparação e dicotomia entre os comportamentos masculino e feminino, o que pode ser observado nas sequências: "uma coisa é o comportamento, o machismo do homem que não sei o quê" e "outra coisa que eu acho é o respeito que a mulher tem que dar pra ela mesma". Para o enunciador, os dois posicionamentos são "coisas diferentes", porque não se relacionam às mesmas regras.

Do ponto de vista discursivo, a dicotomia produzida por Anitta pode ser compreendida, a princípio, como efeito da relação entre formações discursivas diferentes, que impõem restrições distintas para homens e mulheres. No entanto, sustentamos que os posicionamentos construídos pelo enunciador não se configuram a partir de restrições diferentes, e sim segundo as restrições de uma mesma formação discursiva.

Isso porque, apesar de situar homens e mulheres em modelos de conduta diferentes, a dicotomia é marcada por uma contradição que pode ser justificada pela espessura sócio-histórica dos termos "mulher de respeito". Ao mobilizar a expressão "a mulher tem que se dar o respeito", 
o enunciador atualiza um sentido cristalizado historicamente que pode ser descrito como a necessidade de a mulher assumir um comportamento "apropriado" para evitar atitude machista. Logo, o "respeito" de que fala o enunciador pode ser interpretado como um comportamento "recatado" e "discreto", moldado socialmente para "evitar" o assédio e o machismo.

Nesse sentido, a formação deste discurso ("a mulher tem que se dar o respeito") não está em dicotomia com aquele que atesta o comportamento machista do homem. A existência dessas regras de conduta legitima a possibilidade de "punição", pois se a mulher não se dá o respeito, ela pode receber atitudes machistas do homem. Assim, o comportamento da "mulher de respeito" é moldado segundo a posição de autoridade que tem o homem de determinar aquilo que é apropriado ou não à mulher, tendo em vista a possibilidade de assédio a ela.

Considerando esse funcionamento discursivo - o comportamento feminino de "respeito" é determinado pela posição de autoridade masculina de "punição" -, compreendemos que as posições discursivas construídas por Anitta se inscrevem na mesma formação discursiva, e não em formações discursivas distintas. Em suma, os dois discursos são produzidos conforme regras semelhantes sobre quem pode e como pode assumir dadas posições no domínio da sexualidade.

Mais adiante, Pitty comenta os sentidos de "respeito" mobilizados por Anitta, situando-os no contexto das relações de gênero como um dever tanto para homens quanto para mulheres. Comparada às posições instauradas no dizer de Anitta, as posições produzidas nos enunciados de Pitty apresentam uma singularidade: não é só a mulher que tem obrigação de se respeitar, o homem também deve fazê-lo. Entretanto, o sentido de respeito aqui não corresponde ao sentido cristalizado mobilizado nos enunciados de Anitta - respeito como "discrição" sexual -, e sim ao sentido de respeito como apreço e consideração.

Por outro lado, para demonstrar seu ponto de vista, Pitty retoma simulacros construídos sobre o que é ser um(a) homem/mulher de respeito, porém o faz para refutá-los: "Então, isso [sentido de respeito] me incomoda". Para demarcar sua posição de oposição, o enunciador faz comparações entre os simulacros existentes, destacando as diferenças entre eles: "Porque o que se diz de uma mulher de respeito é diferente do que se diz de um cara de respeito". Logo, identificamos no dizer de Pitty simulacros opostos, de maneira que um "homem de respeito é X" e uma "mulher de respeito é Y". 
Tendo em conta a espessura sócio-histórica das materialidades, podemos interpretar os simulacros em função das posições de homens e mulheres tal como legitimadas socialmente. Assim, os simulacros produzem os seguintes sentidos: o simulacro do "homem de respeito" situa-se no âmbito do prestígio social, trata-se de um homem de posição favorecida. Diferentemente, o simulacro da "mulher de respeito" faz referência à mulher alheia a um comportamento considerado "amoral" no campo da sexualidade, sendo marcado por conotação sexual. Os simulacros de "respeito" construídos para homens e mulheres demonstram, portanto, uma distinção que reflete a hierarquia nas posições sociais dos gêneros: de um lado, o poder e o prestígio, de outro, o dever e o estigma.

Além disso, verificamos que o simulacro "mulher de respeito" é também retomado quando o enunciador menciona os efeitos da performance artística de Anitta: "As pessoas te veem no palco rebolando de roupa curta e acham que você está disponível'. Estabelecendo relação com esse enunciado, Pitty produz um enunciado, em seguida, na forma de uma metaenunciação: "Pra mim isso é sair na defesa de um comportamento que se fosse masculino ninguém questionaria". Podemos considerá-lo uma metaenunciação, uma vez que o enunciado constitui comentário do próprio dizer do enunciador com vistas a delimitar seu ponto de vista. Nesse sentido, a posição do enunciador aqui é produzida a partir de um a priori, ou seja, a partir das reações legitimadas socialmente a esse tipo de performance caso fosse um homem.

Com isso, além dos sentidos ligados ao simulacro "mulher de respeito" (rebolar no palco de roupa curta significa que a mulher está disponível), os enunciados também fazem ressoar sentidos associados ao simulacro do "homem de respeito", pois demonstram como seria interpretada a ação se realizada por um homem: "ninguém questionaria". Desse modo, ao construir seu ponto de vista, o enunciador se opõe à "defesa do não julgamento ao comportamento masculino", mobilizando e colocando em antagonismo sentidos sócio-históricos sobre o comportamento sexual masculino (regido por regras mais flexíveis) e o comportamento feminino (marcado por regras mais rígidas e julgamentos de valor).

Tendo em vista a situação de polêmica resultante da interincompreensão regrada, Maingueneau (2005) assinala que os sentidos compreendidos pelos sujeitos de formações discursivas antagonistas dependem de seus respectivos sistemas de restrições semânticas, isto é, cada sujeito só compreende aquilo que pode compreender considerando as 
regras que regem a formação de seus discursos e de seu posicionamento. Desse modo, a interincompreensão ocorre quando sujeitos enunciam ao outro aquilo que "se pode dizer e não se deve compreender": lá onde um sujeito lê um dado sentido, o outro lerá sentidos opostos, habitados por regras e restrições semânticas antagônicas.

Os enunciados em (4) apresentam esse funcionamento ao materializar posições antagonistas sobre o comportamento sexual feminino. É o que podemos identificar em: "Anitta: [...] eu vejo um comportamento feminino que dá margem realmente para o homem achar coisa $x$ ou y da mulher etc." versus "Pitty: Ele está errado! [...] Ele não tem que achar ou achar nada! Quem tem que fazer o que você quer é você, cara!". A instância enunciativa é então configurada com enunciadores marcados por restrições semânticas divergentes, uma vez que leem sentidos distintos sobre o mesmo tema. Assim, temos que: lá onde Anitta vê possibilidade de o homem julgar comportamento feminino, Pitty vê obrigação de não julgamento sobre ação da mulher.

Vejamos esquematicamente as compreensões dos enunciadores sobre o papel do homem de acordo com as posições discursivas de Anitta e Pitty respectivamente:
O homem pode julgar o comportamento da mulher. vs.
O homem não deve julgar o comportamento da mulher.

A situação de polêmica decorre também de processo de interincompreensão quando os enunciadores mobilizam marcas de heterogeneidade mostrada para negar a posição discursiva do Outro, ou seja, para discordar com a posição outra. É o que observamos nas sequências: "Pitty: Anitta, tá errado!" e "Anitta: Eu não concordo...". Neste caso, identificamos situação de polêmica, ou seja, um desacordo entre pontos de vista decorrente das regras das formações discursivas em relação. Os enunciadores colocam em cena duas formas diferentes de interpretar os papéis de gênero, o que gera efeito de incompreensão do ponto de vista outro e, com efeito, de discordância de interpretações. Enfim, o modo como um sujeito traduz o comportamento do Outro (homem e/ou mulher) não corresponde à leitura que faz o coenunciador no fio do discurso. 


\section{Considerações finais}

Neste trabalho, analisamos os enunciados produzidos pelas cantoras Anitta e Pitty sobre comportamento sexual feminino na contemporaneidade e verificamos que seus posicionamentos situamse em formações discursivas antagônicas. Por meio de marcas de heterogeneidade mostrada e de jogos de alteridade, os sujeitos na cena enunciativa materializaram linguisticamente posicionamentos distintos também para homens e mulheres no contexto das relações de gênero.

No primeiro momento, constatamos que Anitta constrói os papéis de gênero de forma heterogênea, pois atualiza discursos tradicionais em relação de coexistência com discursos que atestam a flexibilização nas regras do comportamento sexual da mulher na atualidade. Ademais, observamos que a relação desses discursos no interdiscurso não se dá de forma estável, pois o modo como o Eu inscreve o Outro nesses enunciados evidencia as restrições de uma formação discursiva marcada ora pelo modelo do amor romântico, ora pela moral familiar, fazendo ecoar interdições e rejeição de sentidos ligados a dados comportamentos da mulher no domínio da sexualidade.

No segundo momento, a análise se voltou para a situação de polêmica estabelecida entre as cantoras, que apresentaram leituras diferentes sobre a igualdade de gêneros na atualidade. Nesse ponto, verificamos que a polêmica se dá em função de processo de interincompreensão regrada, uma vez que os sujeitos leem o Outro a partir de restrições semânticas bastante distintas. As regras da formação discursiva que habitam os enunciados de Anitta corroboram possibilidade para o homem julgar o comportamento da mulher. Por outro lado, as regras da formação discursiva que habitam o dizer de Pitty refutam a autoridade masculina de julgamento sobre o comportamento feminino.

A análise constatou ainda que os sujeitos na enunciação mobilizam simulacros da "mulher de respeito", o que contribui para a delimitação de suas posições discursivas e, por conseguinte, de seus pontos de vista sobre o tema. A presença e a rejeição do Outro se deu, nas sequências, de forma mostrada uma vez que os sujeitos em relação refutam explicitamente seu exterior utilizando-se de metaenunciações para fixar e explicar os sentidos que podem produzir a partir da formação discursiva de que falam. 
Nesse sentido, as posições discursivas ocupadas pelos sujeitos evidenciam a heterogeneidade de discursos sobre igualdade/desigualdade de gêneros e a possibilidade de outros sujeitos da situação de enunciação (plateia, apresentador, entrevistadas etc.) de rejeitarem ou se aliarem a essas posições, pois também situados neste momento histórico, marcado pela coexistência de regras rígidas e flexíveis no domínio da sexualidade.

Com isso, concluímos que, do ponto de vista discursivo, os enunciados apresentam funcionamento polêmico porque socialmente, mesmo com transformações na sexualidade, os sujeitos enunciam e compreendem aquilo que podem a partir de formações discursivas distintas e atravessadas por embates entre os gêneros legitimados social e historicamente. As posições discursivas analisadas demonstram que o flexível coexiste com o rígido. Logo, as mudanças no domínio da sexualidade coexistem com o retorno de já-ditos, num movimento tão disperso quanto polêmico dos discursos.

\section{Referências}

AUTHIER-REVUZ, J. Heterogeneidade(s) enunciativa(s). Tradução de Celene Cruz e João Wanderley Geraldi. Cadernos de Estudos Linguísticos, Campinas, n. 19, p. 25-42, jul./ dez. 1990.

. Palavras incertas: as não-coincidências do dizer. Tradução Claudia Castellanos Pfeiffer et al. Campinas: Unicamp, 1998.

BENVENISTE, E. Problemas de linguistica geral I. Tradução Maria da Glória Novak e Maria Luiza Neri. Campinas: Pontes, 1995.

BOURDIEU, P. A dominação masculina. Tradução Maria Helena Kühner. 2. ed. Rio de Janeiro: Bertrand Brasil, 2002.

FOUCAULT, M. A arqueologia do saber. Tradução Luiz Felipe Baeta Neves. 8. ed. Rio de Janeiro: Forense Universitária, 2012.

GIDDENS, A. A transformação da intimidade: sexualidade, amor e erotismo nas sociedades modernas. Tradução Magda Lopes. São Paulo: Unesp, 1992.

LAURETIS, T. D. Tecnologia do gênero. In: HOLLANDA, H. (Org.). Tendências e impasses: o feminismo como crítica da cultura. Rio de Janeiro: Rocco, 1994. p. 206-242.

LÉVI-STRAUSS, C. As estruturas elementares de parentesco. Tradução Mariano Ferreira. 9. ed. Petrópolis: Vozes, 1982. 
MAINGUENEAU, D. Novas tendências em Análise do Discurso. Tradução Freda Indursky. 2. ed. Campinas: Pontes, 1993. 2005. . Gênese dos discursos. Tradução Sírio Possenti. Curitiba: Criar,

NEVES, M. H. M. Imprimir marcas no enunciado. Ou: A modalização na linguagem. In: . Texto e gramática. São Paulo: Contexto, 2006. p. 151-160.

PÊCHEUX, M. Semântica e discurso: uma crítica à afirmação do óbvio. Tradução Eni Pulcinelli Orlandi. 3. ed. Campinas: Unicamp, 1997.

PROGRAMA ALTAS HORAS. Anitta e Pitty discordam em debate sobre liberdade sexual feminina. 2014. Disponível em: <http://globotv. globo.com/rede-globo/altas-horas/v/anitta-e-pitty-discordam-em-debatesobre-liberdade-sexual-feminina/3815453/>. Acesso em: 15 jul. 2015.

RIBEIRO, C. F. F. A família contemporânea brasileira: mães chefes de família de camada média. 2005. 176 f. Dissertação - Faculdade de Educação, Universidade Estadual de Campinas, Campinas, 2005. 